\title{
Blockchain-Based Initiatives in Social Security Sector
}

\author{
Mohammed Shuaib ${ }^{1}$, Shadab Alam², Salwani Mohd \\ Daud $^{3}$, Sadaf Ahmad ${ }^{4}$ \\ \{talkshuaib@gmail.com ${ }^{1}$, s4shadab@gmail.com², \\ Salwani.kl@utm.my ${ }^{3}$, sadafahmadsecurity@gmail.com² ${ }^{2}$ \\ Razak Faculty of Technology and Informatics (RFTI), University \\ Teknologi Malaysia (UTM), Kuala Lumpur, Malaysia ${ }^{1,3}$ \\ Department of Computer Science, Jazan University, Jazan, KSA², \\ Department of Computer Science, Aligarh Muslim University, Aligarh, \\ India $^{4}$
}

\begin{abstract}
Blockchain technology has emerged as a major technological platform that can record the various transaction and records in a secure and immutable format. It is being used in all sorts of transaction and record management in multiple fields. Social security is a domain that requires a system to correctly validate and store records in a secure and tamper-proof manner to avoid any case of fraud and to reach it to genuinely intended applicants. Blockchain technology can provide such a platform. In this paper, various existing projects in the field of social security have been reviewed and analysed that presents a futuristic approach for blockchain applications in the social security sector.
\end{abstract}

Keywords: Blockchain, social security, security, privacy, ledger

\section{Introduction}

Blockchain Technology allows various entities [nodes] in a system to make transactions of digital assets among multiple participants using P2P networks that stores transactions in a distributed manner within the network [1]. Public key cryptography and Digital signature techniques are employed to register the ownership and ownership transfer details on ledger [2].

These transactions are approved and validated by consensus mechanism, and when a new transaction takes place, participating nodes validate it. Once approved by the nodes, these transactions are defined into a node and added into the existing blockchain. This mechanism ensures that the latest details are updated and approved by the participating entities of blockchain [3]. The entire nodes store a copy of these block stored in the form of blockchain. Time stamping and hashing technique are used to secure these transaction details [4]. Mining is a term used for the creation of new blocks. Hashing and time stamping techniques ensure that any alteration in blocks is detected easily [5]. 
Decentralised storage of records is done in blockchain; therefore, there is no chance for hackers to violate its security, and if one node is down, it does not affect the entire blockchain [6]. The P2P based architecture helps in security as well as the immutability of recorded transactions in a blockchain. There are various forms of distributed consensus protocols such as majority voting; priority voting or having a minimal number of votes that is used for validation of new nodes ensures the data integrity of the transactions.

Blockchain can be defined as a distributed database on the internet. It maintains and updates all the transaction that occurs across the peer-to-peer network. These networks can be public or private based on the control structure of the network [7]. Blockchain technology does not require any intermediary to ensure security, privacy and trust in transactions [8]. It can ensure security of data and maintain a reliable history of past transactions that have triggered a massive interest from the industry side [9].

The main motive for adopting the $\mathrm{BC}$ Technology is the transparent real-time transaction settlement and self-executing smart contracts [10]. Another primary motivation to adapt is its potential benefits in social and economic activities of the society.

Blockchain can counter the deficiencies in the existing transaction and record managements systems and provide effective management in public service activities [11]. The blockchain-based framework can effectively verify the various data correctly for citizens, private companies, and governments. It will further reduce the operation cost drastically by eliminating the chances of fraud and facilitating transparent transactions between various entities.

Blockchain technology provides a secure and decentralised environment for data. It was initially designed for digital currency transactions, but now it is being used for safe and reliable transaction management in many areas like the land record, egovernance, Internet of Things [12,13], smart home, smart city, cloud storage and clod computing [14,15], educational systems and healthcare [16, 17], Internet of Vehicles (IoV) [18].

Throughout the world, various governments are working on a project investigating the possible applications of Blockchain technology in e-governance and public services and exploring its potential [19]. These projects focus on various aspects like e-health, land registry etc. Still, these projects are in the initial phase, and no common framework has proposed due to various security and implementation challenges [20].

Various countries are trying to develop their own blockchain framework for its application, but at the same times, it's creating a hurdle in integration and data exchange that requires some sort of standardisation.

\section{Social Security Domains}

Social Security has various domains that have been discussed in this section.

\subsection{Water Application}


The blockchain use in water application is a new initiative in the water application. Blockchain technology can be used by governments to track and record of water consumption data and population ratio in a specific locality and for creating better- organized supply chain for public according to the need and availability of water. Governments can detect and monitor specific

\subsection{Education}

Blockchain can automate the attendance process and issuing of degrees and transcripts in the educational institutes. Blockchain provides a secure and efficient method to access the attendance and results from the record that will reduce the efforts by the educational institutes for the verification of these records [21]. Currently, many organizations are providing blockchain-based certification. For example, Edgecion is providing blockchain-based certification. Blockchainbased certificates will help in detecting counterfeit certificates and help companies in getting instant verification of these records.

\subsection{Human Rights}

Human right challenges like stopping human trafficking, stopping slavery, providing reasonable housing to the needy, funding for the bail of the prisoners having less income can be solved by using Blockchain [22].

As in blockchain-based human rights implication, the tracking and raising of funds can be tracked also provides a medium to track the individual's claim of rights violations. For example, Stop the Traffic recommends for the creation of a traceable t-shirt supply using blockchain that will offer the labourers to confirm that their labour rights have been respected during the production process of cotton harvesting to garment production.

\section{Challenges in Blockchain application in Social Security Sector}

There are various challenges in the adaptation of blockchain technology in the social security sector that need to analysed and investigated before its proper utilisation in this sector. These challenges have been presented in this section.

\subsection{Standardization of the Technology}

Standardisation of technology is a major concern that can allow interconnectivity among various parties like teachers, learner, government; employers while taking into account the needs and benefits. Only a standardised process and technology, keeping in mind the needs of all parties can harness the full potential of technology. Lack of standardization will not allow any sort of intercommunication and hinder in the creation of an ecosystem of digital credentials [23].

\subsection{Resource Usage and Complexity}

Since each node of blockchain is to be stored on the network that makes high storages costs, and more computation power is required for the cryptographic process. It will require more electric consumption and hazardous environmental calamity increasing cost and complexity [24].

\subsection{Third party's dependencies}

Since blockchain will remove the involvement of any party for the controlling of the ledger, but in public blockchain permits any person for the formation and 
authentication of a node on the entire network. There are lots of barriers like technical knowledge and resource, which will force the people to take help of blockchain specialized companies [24].

\subsection{Security Challenges}

Security is one of most essential aspect that need to be reviewed and ascertained before any implementation. Although blockchain technology is considered secure in comparison to other technologies but still there are various security concerns that need to be considered and countermeasures to be applied to make it secure and reliable that also applies to social security domain also [25].

\section{Blockchain Initiatives in Social Security Sector}

Some of the currently running blockchain-based social security projects have been summarised in this section.

- The University of Melbourne has started an initiative named "Academic credentials" using blockchain to store and verify copies of academic qualification with the companies and other third parties in tamper-proof structure. The University of Melbourne is the first in the world to adopt the blockchain technology in academics that will improve the trust in the University of Melbourne. University is developing this system in collaboration with the Massachusetts Institute of Technology Media Lab. This initiative in an initial stage [26].

- Australian national transport commission has started an initiative named "Land Transport Regulation 2040" to provide charging and funding public transportation model that will be more secure, sustainable, transparent and reliable using blockchain. It also provides a medium for secure communication between the transporters and transport service providers. The project is in its initial stage [27].

- Thailand Post and State Railway have taken the initiative named "Blockchain and IoT for Railway Logistics" using IoT and Blockchain technology to improve the Logistics service in the Thailand post and the exact time of arrival and delay information related with trains and logistics that can be conveyed accurately to the people. This initiative is in the Initial stage [28]

- United States Department of Homeland Security and Directorate and the Domestic Nuclear Detection Office started, and initiative named "Applicability of Blockchain Technology to Privacy Respecting Identity Management" using blockchain technology in identity verification that will increase the security and efficiency also reduces the security risk and costs involved related with the Homeland security [29]

- Gemeente Schiedam \& Drechtsteden municipalities, Netherland have started an initiative named "Parking Spaces for Disabled Citizens" to provide benefits of Public transportation and parking spaces to the disabled citizens by utilising blockchain technology that can provide an improved method for the allocating and controlling of parking spaces for the disabled and to provide the individual parking facilities to the disabled person. This initiative is in its development stage [30]. 
- Human Environment and Transport Inspectorate of Netherland started an initiative named "Truck Driver Tracking" system for the tracking of working and resting hours of truck drivers using blockchain. This initiative is in the development stage.

Table 1. Blockchain initiatives in the social security sector

\begin{tabular}{|c|c|c|}
\hline Country & Government Entity & Project Name \\
\hline Australia & $\begin{array}{l}\text { Australia National } \\
\text { Transportation }\end{array}$ & $\begin{array}{l}\text { Land Transport Regulation } \\
2040\end{array}$ \\
\hline Malta & $\begin{array}{l}\text { Ministry for Education } \\
\text { and Employment }\end{array}$ & $\begin{array}{l}\text { Educational \& Government } \\
\text { Digital Certificates }\end{array}$ \\
\hline Netherlands & $\begin{array}{l}\text { Gemeente Schiedam \& } \\
\text { Drechtsteden }\end{array}$ & $\begin{array}{l}\text { Parking Spaces for Disabled } \\
\text { Citizens }\end{array}$ \\
\hline Netherlands & $\begin{array}{l}\text { Human Environment and } \\
\text { Transport Inspectorate }\end{array}$ & Truck Driver Tracking \\
\hline Netherlands & $\begin{array}{l}\text { Kadaster: Land Registry } \\
\text { and Mapping Agency }\end{array}$ & Ship Registration \\
\hline Russia & $\begin{array}{l}\text { Federal Antimonopoly } \\
\text { Service }\end{array}$ & Digital Ecosystem Pilot Project \\
\hline Thailand & $\begin{array}{l}\text { Thailand Post, State } \\
\text { Railway of Thailand }\end{array}$ & $\begin{array}{l}\text { Blockchain and IoT for } \\
\text { Railway Logistics }\end{array}$ \\
\hline $\begin{array}{l}\text { United States - } \\
\text { Federal }\end{array}$ & $\begin{array}{l}\text { Department of Homeland } \\
\text { Security [DHS]: Science } \\
\text { and Technology [S\&T] } \\
\text { Directorate and the } \\
\text { Domestic Nuclear } \\
\text { Detection Office [DNDO] }\end{array}$ & $\begin{array}{l}\text { Applicability of Blockchain } \\
\text { Technology to } \\
\text { Privacy Respecting Identity } \\
\text { Management }\end{array}$ \\
\hline $\begin{array}{l}\text { United States - } \\
\text { State } \\
\text { Government }\end{array}$ & $\begin{array}{l}\text { State of Texas: University } \\
\text { of Texas - UTx }\end{array}$ & $\begin{array}{l}\text { Academic Records - } \\
\text { ChainScript TM }\end{array}$ \\
\hline
\end{tabular}

\section{Blockchain Initiative Progress in Social Security Sector}

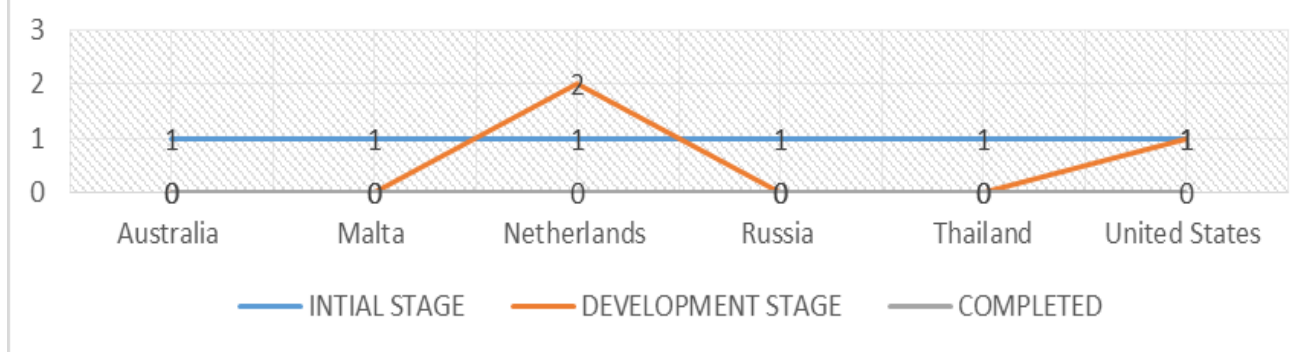


Figure1: Blockchain Initiatives progress in Social Security sector

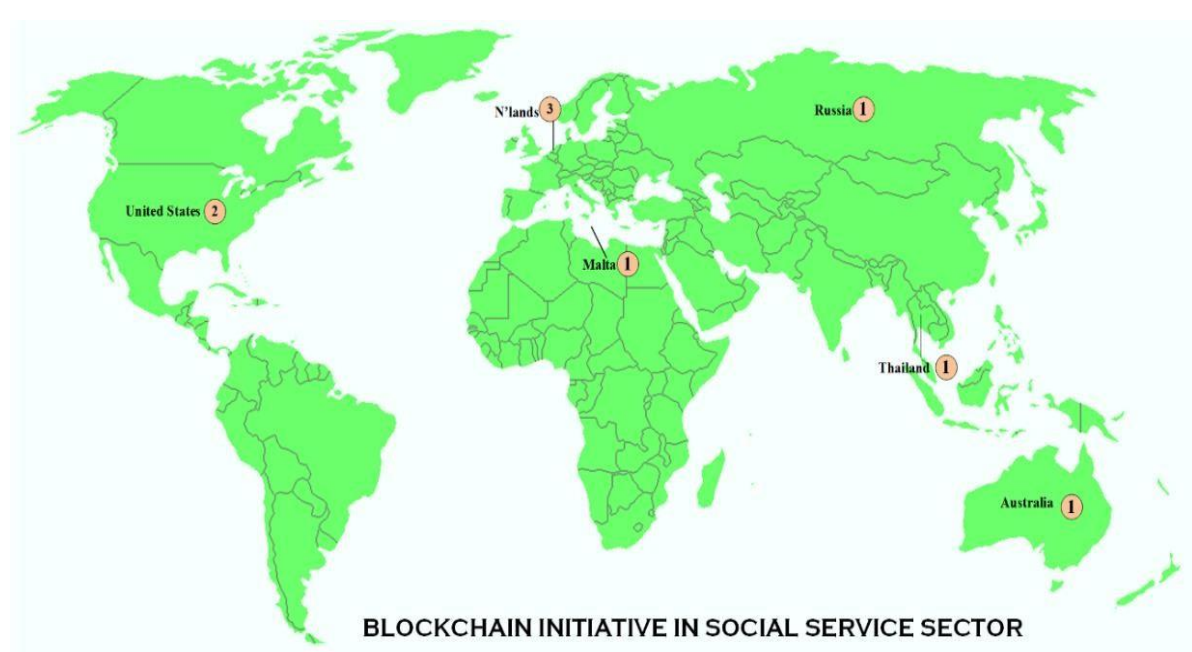

Figure 2: Blockchain Initiatives progress in the social security sector [map]

\section{Conclusion}

This research paper highlights the major aspects of the social security sector that where blockchain technology can be applied and challenges that need to be resolved for successful implementation of blockchain technology implementation in the social security domain. Further, this paper reviewed the technical aspects of existing blockchain-based social security sector projects. Blockchain is a promising technology that can be successfully implemented in the social security sector to resolve the bottlenecks and issues of administrative issues in this sector like proper and unique identification of beneficiaries and fund management issues in this sector.

\section{References}

[1] Back A, Corallo M, Dashjr L, Friedenbach M, Maxwell G, Miller A, et al. Enabling blockchain innovations with pegged sidechain s. URL: http://www opensciencereview com/papers/123/enablingblockchain-innovations-with-pegged-sidechains. 2014:72.

[2] Warburg B. How the blockchain will radically transform the economy. TED Summit. 2016.

[3] Buterin V. A next-generation smart contract and decentralized application platform. white paper. 2014;3:37.

[4] Maetouq, Ali, et al. "Comparison of Hash Function Algorithms Against Attacks: A Review." International Journal of Advanced Computer Science and Applications, br 8 (2018).

[5] Narayanan A, Bonneau J, Felten E, Miller A, Goldfeder S. Bitcoin and cryptocurrency technologies: a comprehensive introduction: Princeton University Press; 2016.

[6] Ølnes S, editor Beyond bitcoin enabling smart government using blockchain technology. International Conference on Electronic Government; 2016: Springer.

[7] Srisukvattananan Y. Overview of blockchain and possible use cases in the Thai payment system: Massachusetts Institute of Technology; 2016. 
[8] Kosba A, Miller A, Shi E, Wen Z, Papamanthou C, editors. Hawk: The blockchain model of cryptography and privacy-preserving smart contracts. 2016IEEE symposium on security and privacy (SP); 2016: IEEE.

[9] Crosby M, Pattanayak P, Verma S, Kalyanaraman V. Blockchain technology: Beyond bitcoin. Applied Innovation. 2016;2(6-10):71.

[10] Wyman O. Blockchain in capital markets: the prize and the journey. Euro Clear. 2016.

[11] Drucker P. Blockchain applications in the public sector. Deloitte, London[Google Scholar]. 2016.

[12] Siddiqui, Shams Tabrez, et al. "Security Threats, Attacks, and Possible Countermeasures in Internet of Things." Advances in Data and Information Sciences. Springer, Singapore, 2020. $35-46$

[13] Alam, Shadab, et al. "Internet of Things (IoT) Enabling Technologies, Requirements, and Security Challenges." Advances in Data and Information Sciences. Springer, Singapore, 2020. 119-126.

[14] Gupta,a. K., Siddiqui,S.T., and Shuaib, M. "Cloud Computing Security using Blockchain", Journal of Emerging Technologies and Innovative Research, Volume 6, Issue 6, 2019.

[15] Shuaib, Mohammed, et al. "Why adopting cloud is still a challenge? - A review on issue and challenges for cloud migration in organizations." Ambient Communications and Computer

[16] Turkanović M, Hölbl M, Košič K, Heričko M, Kamišalić A. EduCTX: A blockchain-based higher education credit platform. IEEE access. 2018;6:5112-27.

[17] Dorri A, Kanhere SS, Jurdak R, Gauravaram P, editors. Blockchain for IoT security and privacy: The case study of a smart home. 2017 IEEE international conference on pervasive computing and communications workshops (PerCom workshops); 2017: IEEE.

[18] Samad, Abdus, et al. "Internet of vehicles (IoV) requirements, attacks and countermeasures." Proceedings of 12th INDIACom; INDIACom-2018; 5th international conference on "computing for sustainable global development" IEEE conference, New Delhi. 2018.

[19] Jun M. Blockchain government-a next form of infrastructure for the twenty-first century. Journal of Open Innovation: Technology, Market, and Complexity. 2018;4(1):7.

[20] Mazlan, Ahmad Akmaluddin, et al. "Scalability Challenges in Healthcare Blockchain System-A Systematic Review." IEEE Access (2020).

[21] Lab IC. Managing Our Water Supply With Blockchain - Impact Chain Lab - Medium. 2017.

[22] Tonar ET, Remington. Why Blockchain Is Key To Transforming How Physical Infrastructure Works And How We Think About It: @forbes; 2019 [Available from: https://www.forbes.com/sites/ellistalton/2018/01/22/why-blockchain-is-key-to-transforminghow-physical-infrastructure-works-and- how-we-think-about-it/.

[23] Schmidt J. Credentials, Reputation, and the Blockchain. 2017.

[24] Grech A, Camilleri AF. Blockchain in education. Luxembourg: Publications Office of the European Union; 2017.

[25] Siddiqui,S.T., Shuaib, M, and Alam,S, "Blockchain Security Threats, Attacks and Countermeasures", 4th International Conference on Recent Advancements in Computer, Communication and Computational Sciences, (RACCCS-2019) Springer, Ambient Communications and Computer Systems, Advances in Intelligent Systems and Computing, August 16-17, 2019

[26] Melbourne TUo. Melbourne University to pilot a distributed database for microcredentials: @ unimelb; 2017 [updated 29 Jan 2019 8:43am. Available from: https://about.unimelb.edu.au/newsroom.

[27] Regulation LTJFpNANTCO. 2040 Technology, trends and other factors of change. 2016.

[28] nguansuk Sl. Rail and Post to use IoT, blockchain: @BangkokPostNews; 2017 [Available from: https://www.bangkokpost.com/business/telecom/1307071/rail-and-post-to-use-iot-blockchain

[29] Jacobovitz OJTL, William Frankel Center for Computer Science Department of Computer Science. Ben-Gurion University BS. Blockchain for identity management. 2016 